\title{
The Relationship between Clinical Instructors Teaching Behaviors and Nursing Students Motivation for Learning as Perceived by Nursing Students
}

\author{
ABD ELMONGY S. BAZA, M.Sc. and ISMAIL M. ABD EL-MEGEED, D.N.Sc.
}

The Department of Nursing Administration, Faculty of Nursing, Cairo University

\begin{abstract}
Background: Clinical instructors are vital in teaching learning process of nursing students. Their teaching behaviors are of interest for the students; as students' knowledge, skills and attitudes are formed during clinical training that prepare them for their future roles of caring patients with high quality; so we need to study student's motivation for learning in relation to teaching behaviors of clinical instructors.
\end{abstract}

Aim of Study: To assess the relationship between teaching behaviors of clinical instructors and students motivation for learning as perceived by nursing students.

Subjects and Methods: A descriptive correlational cross sectional design was utilized to collect data from fourth year nursing students (140 students) at the Faculty of Nursing, AlAzhar University. Data was collected by using two tools: Nursing Clinical Teacher Effectiveness Inventory (NCTEI) and nursing student's motivation questionnaires.

Results: There was motivation for learning among nursing students in relation to teaching behaviors of clinical instructors as students perceived that nursing competencies of their clinical instructors had priority in relation to their motivation for learning.

Conclusion: We can conclude from this study that there was positive relation between teaching behaviors of clinical instructors and student's motivation for learning.

Recommendations: Orientation program should be prepared for newly clinical instructors according to student's needs. Periodic clinical instructors' evaluation is necessary to evaluate their behaviors, incorporate behaviors needed into practice.

Key Words: Clinical instructor-Motivation to learn - Teaching behavior.

\section{Introduction}

NURSES will be able to provide high-quality patient care at clinical work if they have received high-quality teaching during their course of study. They should have competence that enable them to

Correspondence to: Dr. Abd Elmongy S. Baza,

The Department of Nursing Administration,

Faculty of Nursing, Cairo University promote health of people they care for. The competence of nurses is based on knowledge and skills acquired during their education. Application of nursing skills starts in a clinical learning environment at the university hospitals and continues in a clinical work, where they continuously learn on the job [1]. Clinical teaching is at the fundamental of the nursing profession with almost $50 \%$ of nursing educational programs devoted to this topic. At the clinical teaching stage, students gain the required experience by learning clinical skills and taking up opportunities to apply their theoretical knowledge into practice through mental, motor and social skills necessary for the delivery of patient care. On the other hand, instructors' characteristics are directly related to learning and gaining skills [2].

Clinical instructor plays an essential role in the production and training of competent nurses. Students observed the behavior of their clinical instructors and adopt those behaviors in their future lives [3]. As students are the straight recipients of clinical instruction, they are in a good position to observe their clinical instructors. Therefore it is very important for clinical instructors to demonstrate effective clinical teaching behaviors while preparing students to practice in a complex heath care system [4].

There is no doubt that student motivation is the only most essential part of students learning. Learning is principally hard work; it is pushing the brain to its parameters, and thus can only happen with motivation. Students who are highly motivated will learn willingly, and make any class fun to learn, unlike students who are unmotivated will learn very little and generally make learning more terrible and frustrating. Fortunately, research studies indicated that there are many things a clinical instructor can do to motivate their students to learn; 
so clinical instructor should be an expert in the issue, he must be qualified to show students why the material is important, intellectually interesting, and valuable for them to learn. Transmission of this message is an important goal of any effective instructor [5]

It is evident from many studies that there was a positive relation between the behaviors of clinical instructor which they frequently used and learning process of student in the clinical setting in general but not on the student motivation to learn [3].

\section{Significance of the study:}

Clinical instructors were playing a dynamic role in teaching nursing students and they affect their knowledge, skills, and attitudes. However the clinical instructor's behaviors might not matched with students needs and it may affect their effectiveness in learning process that comes from their motivation to learn, so it is important to identify the relationship between the teaching behaviors of the clinical instructors and its effect on student's motivation for learning. This will help to derive the basic behaviors that needed to motivate students learning in the clinical setting that facilitate preparing future nurses for their roles. The findings of the present study will provide base for all clinical instructors to inspect and change their own behaviors regarding clinical practice and to understand teaching behaviors that are operative in clinical practice [6]

Therefore, it could help to establish mutual and perfect expectations among the students and clinical instructors which could help to create a well academic atmosphere contributing to effective learning. This will give indication that the body of knowledge related to effective clinical instructor's behaviors; and so the college can make an orientation programs for newly clinical instructor regarding effective clinical instructor's characteristics to improve the learning process. In addition, it will maximize openings for nursing students to learn well, and succeed in becoming professional nurses throughout learning in the clinical settings which will be the place of work in the near future.

\section{Research questions:}

1- What is the perception of nursing students about their clinical instructors teaching behaviors?

2- What is the perception of nursing students about motivators for learning?

3- Is there a relationship between teaching behaviors of clinical instructors and nursing student's motivation for learning?

\section{Subjects and Methods}

Research design:

A descriptive correlational cross sectional design was utilized for this study.

Setting:

This study was carried out at the Faculty of Nursing, Al-Azhar University, which includes 7 Nursing Departments (Fundamental, Medical Surgical, Pediatric, Obstetric, Community, Psychiatry And Administration). Data was collected at the beginning of the second term of study at 15-22019, after taking committees permissions.

\section{Subjects:}

Purposive sampling technique was used to recruit all fourth year nursing students (140 students) to be the study sample. Students who are involved in the study passed clinical training through the previous 3 years and the first term of the fourth year.

\section{Tools of data collection:}

Data was collected using two tools including demographic sheet:

Demographic sheet: Developed by the researcher this includes the personal data about the students (age, marital status, and if student in the fourth year for the first time, or repeater).

1st Tool: The Nursing Clinical Teacher Effectiveness Inventory (NCTEI). It was developed by Knox and Mogan (1987). It was used to rate the clinical instructors teaching behaviors. It has five dimensions (teachingabilities (17 items), nursingcompetencies (9 items), personality ( 7 items), evaluationabilities (8 items), interpersonal relations (5 items) [7]. Students answered the 5-points likerttype scale (strongly agree $=4$, agree $=3$, neutral $=2$, disagree $=1$, strongly disagree $=0$ ). Scoring system less than $60 \%$ is considered low priority teaching behavior, from $60 \%-75 \%$ is considered moderate, and over $75 \%$ is considered high priority teaching behavior.

2nd Tool: Nursing student's motivation questionnaires developed by Zaki S (2015). It was used to collect data from students about their motivation for learning by rating their agreement on 40 items that were categorized into 4 dimensions (participation with others (10 items), efficiency \& effectiveness (11 items), sense of responsibility (10 items), interest in general activities (9 items) [8] Students answered the 5-points likert-type scale (strongly agree $=4$, agree $=3$, neutral $=2$, disagree $=1$, strongly disagree $=0$ ). Scoring system less than 
$60 \%$ is considered low motivated, from $60 \%-75 \%$ is considered moderate, and over $75 \%$ is considered highly motivated.

\section{Validity and reliability:}

The two tools are valid as they were used previously. NCTEI was used by (Ismail LN, et al., 2016, Hassan S, 2015, Al-Hamdan-Z, 2014, Fowler J, 2009 Bawadi H, 2000 et al.1), and motivation tool was used by Zaki S (2015). About the reliability of the tools, chronbachs alpha test was made. It was (.98) for NCTEI and (0.70) for motivation tool which was appropriate enough to confirm internal consistency of associated scores.

\section{Procedures:}

Once the necessary official approval was obtained from the dean of the faculty, also an approval obtained from every student at the fourth year to agree to participate in the study, the questionnaire sheets were individually distributed to the students at their break time. The aim and nature of the study were explained to students to facilitate data collection. Each student took from 20-30 minutes to complete the questionnaires. Students were advised not to write down their names and not to specify the names of their clinical instructors on the questionnaire sheets in order to ensure anonymity and confidentiality. Data were collected on one day to avoid any bias as history, and then the filled sheets were collected by the researcher.

\section{Ethical consideration:}

The initial approval was taken from ethics and research committees. Each potential subject was informed about the purpose, procedure, benefits, and nature of the study. The researcher emphasized that participation in the study is voluntary, and participant can refuse to participate in the study without any reason stating the possibility to withdraw at any time, and obtained data will be only used for the research purpose. Subjects were assured that this data will not be reused in another research without taking permission of them and the participation is with no risk, also, confidentiality as well as anonymity of the subject is assured through coding of all data and an oral informed consent were obtained, the results of this study will be informed to them.

\section{Statistical analysis:}

Data were verified prior to computerized entry. The statistical package for social sciences (SPSS version 20) was used for that purpose, followed by data analysis and tabulation. Descriptive statistics were applied e.g. (mean, standard deviation, frequency) as well as inferential statistics (person correlation coefficient) were applied between the variables.

\section{Results}

The results of the current study indicated that most fourth year nursing students were single with a rate of $99 \%$ except one of them who was married (1\%), their ages are between $20-23$ years with a mean of 21.56 and SD .637. All of them studied the fourth year for the first time (Table 1).

Table (1): Socio demographic characteristics of fourth year nursing students $(\mathrm{N}=140)$.

\begin{tabular}{lll}
\hline Characteristics & Number & Percentage \\
\hline Age & 140 & $\begin{array}{l}\text { Mean (21.56) } \\
\text { SD (.637) }\end{array}$ \\
Marital status & Single (139) & $99 \%$ \\
& Married (1) & $1 \%$ \\
Year for first time/repeater & 140 (for first time) & $100 \%$ \\
\hline
\end{tabular}

The results indicated that the highest mean percentage for students perception of teaching behaviors of their clinical instructors was personality characteristics $(84 \%)$ followed by evaluation abilities (83.5\%), interpersonal relations $(83.5 \%)$, then nursing competencies (83\%) and teaching abilities (82\%) (Table 2).

Table (2): Mean, SD, mean percentage of student's perception of teaching behaviors of their clinical instructors $(\mathrm{N}=140)$.

\begin{tabular}{llcccc}
\hline Teaching behaviors & Min & Max & Mean & SD & Mean percentage \\
\hline Teaching abilities & 1.65 & 4 & 3.28 & .62 & $82 \%$ \\
Nursing competencies & 1.3 & 4 & 3.32 & .68 & $83 \%$ \\
Evaluation abilities & .88 & 4 & 3.34 & .70 & $83.5 \%$ \\
Personality & 1.7 & 4 & 3.37 & .68 & $84 \%$ \\
Interpersonal relations & .2 & 4 & 3.34 & .65 & $83.5 \%$ \\
\hline
\end{tabular}

The results also indicated that the highest mean percentage for students perception of motivation for learning was for responsibility (73\%) followed by effectiveness $(72.8 \%)$, then sharing with others (64\%), and sharing in public activities (56\%) (Table 3).

Table (3): Mean, SD, mean percentage of student's perception of motivation for learning $(\mathrm{N}=140)$.

\begin{tabular}{lccccc}
\hline Students motivation & \multicolumn{4}{c}{ Min Max Mean SD Mean percentage } \\
\hline Share with others & 1.7 & 3.90 & 2.48 & .52 & $64 \%$ \\
Effectiveness & 1.6 & 3.64 & 2.65 & .32 & $72.8 \%$ \\
Responsibility & 1.8 & 3.80 & 2.78 & .42 & $73 \%$ \\
Share in public activities & .67 & 3.89 & 2.16 & .46 & $56 \%$ \\
\hline
\end{tabular}


The results assured the relation between teaching behaviors of clinical instructors and nursing student's motivation for learning as they perceived that nursing competencies of their clinical instructors has priority in relation to their motivation for learning with $r=.356^{* *}, p=0.00$, then teaching abilities with $r=.310^{* *}$, and $p=.000$ then personality characteristics with as $r=.280^{* *}, p=.001$, and evaluation abilities with as $r=.253^{*} *, p=0.03$. On the other hand, interpersonal relations have a weak relation to student's motivation for learning (Table 4).

Table (4): Relationship between clinical instructors teaching behaviors and students motivation for learning $(\mathrm{N}=140$.

\begin{tabular}{|c|c|c|c|c|}
\hline $\begin{array}{l}\text { Teaching } \\
\text { behaviors }\end{array}$ & $\begin{array}{l}\text { Share } \\
\text { with } \\
\text { others }\end{array}$ & Effective & $\begin{array}{c}\text { Respon- } \\
\text { sibility }\end{array}$ & $\begin{array}{l}\text { Public } \\
\text { activity }\end{array}$ \\
\hline \multicolumn{5}{|l|}{ Teaching abilities: } \\
\hline$r$ & $-.214^{*}$ & -.005 & $.289 * *$ & $.310^{* *}$ \\
\hline$p$ & .011 & .956 & .001 & .000 \\
\hline \multicolumn{5}{|l|}{ Nursing competencies: } \\
\hline$r$ & $-.210^{*}$ & -.042 & $.244 * *$ & $.356^{* *}$ \\
\hline$p$ & .013 & .619 & .004 & .000 \\
\hline \multicolumn{5}{|l|}{ Personality: } \\
\hline$r$ & $-.254 * *$ & .001 & $.202 *$ & $.280 * *$ \\
\hline$p$ & .002 & .991 & .017 & .001 \\
\hline \multicolumn{5}{|l|}{ Evaluation abilities: } \\
\hline$r$ & -.138 & -.136 & $.219 * *$ & $.253 * *$ \\
\hline$p$ & .105 & .108 & .009 & .003 \\
\hline \multicolumn{5}{|l|}{ Interpersonal relations: } \\
\hline$r$ & -.105 & -.123 & .074 & .114 \\
\hline$p$ & .215 & .147 & .385 & .180 \\
\hline
\end{tabular}

\section{Discussion}

The present study aimed to assess the relationship between teaching behaviors of clinical instructors and nursing student's motivation for learning as perceived by nursing students.

All students included in the study were females as the faculty only accept females. They all were single not married. They have passed three years clinical training in nursing and the first semester of the fourth year as the data were collected at the beginning of the last semester. All these students are at fourth year for the first time.

The results of the study revealed that nursing students perceived their clinical instructors teaching behaviors with a mean percentage higher than their motivation for learning. This means that teaching behaviors of their clinical instructors not based on their needs. These results also assured the relation between teaching behaviors of clinical instructors and nursing student's motivation for learning as they perceived that nursing competencies of their clinical instructors has priority in relation to their motivation for learning, then teaching abilities, then personality characteristics, and evaluation abilities. While interpersonal relations have a weak relation to student's motivation for learning.

These results were in agreement with Prabha D., Bhari V., Ponchitra, R., Divya, K., \& Singh S. (2016) whose findings showed that, to improve clinical skills of nursing students, it is necessary to identify clinical teaching behaviors of clinical instructors [4]. Another study Madhat G.K., Shukri R.K., Hayudini J. \& Narayanan S.K. (2013) concluded that clinical competencies of clinical instructors are of primary importance as they are considered as good role models for their students as well as their credibility as good teachers [9] Another researcher, Nelson N. (2011) stated that learning in the clinical setting required knowledgeable and experienced clinical instructors with the ability to teach adult learners effectively. He summarized that nursing student's perceived teaching abilities of the clinical instructor as the second ranked behavior [10]

The study findings also showed that the personality of the clinical instructors has the third priority for the students, this result agree with the results of Asia Pacific Journal (2017) which show that clinical supervisory present especially during thorough physical role of clinical instructors significantly contributes to assessments and implementation of nursing care improving the students' skills while assisting them plan experience the realization of their profession [11]. Ali Akbari F, Parvin N, Heidari M. \& Haghani F. (2015) studied learning theories application in nursing education reveals that learning process needs clinical instructor who had self-discovery and should be emotionally ready to be honest with the students, share his/her expectations and feeling with them comfortably and value their feelings and desires, the role of clinical instructor changes from an instructor and an evaluator into a facilitator of learning and should also be a part of the community of learners, students [12]. This might be not agree with the present study as the results revealed weak positive relation and some inverse relation between interpersonal relations as a teaching behavior of the clinical instructors and motivation factors of students for learning.

Hanifi N., Delkhosh M. \& Parvizy S. (2018) in his study determined the backgrounds and outcomes of the concept of motivation for the clinical education of nursing students, providing an oppor- 
tunity for the evaluation, application, and development of tools using this concept. Motivation for clinical education in nursing students leads to interactions between the psychological conditions of individuals and their spiritual beliefs. These interactions occur mainly between clinical instructors and their students [13]. This result was in agreement with the present study as it showed that student's motivation for learning is important to the students to participate into public activities, having sense of responsibility, and sharing with others.

Clinical teaching has been suggested as an important factor influencing student's motivation and performance. Orsini C., Evans P., \& Jerez O. (2015). Illustrated that research on academic motivation has been focused in general higher education, psychology education and to a lesser extent in medical, dental, and nursing education. They suggested that clinical instructors should interact with their students in a more 'human centered' teaching style, as these actions predict motivational internalization [14], this study confirmed the results of the present study as the student's sense of responsibility during clinical training and their participation as factors of motivation for learning has a relation to clinical instructor's presence in the clinical area and their teaching behaviors. The present results were also supported by Al-Hamdan Z., Fowler J., Bawadi H., Norrie P., Summers L., \& Dowsett D. (2014). They prevailed from their article that $59 \%$ of the study participants were stated that demonstration of clinical skill, giving confidence to students, and having good communication skills is very important for clinical instructors and it affect the students motivation for learning, performance exactly [15] .

Regarding the relationship between teaching behaviors of clinical instructors and student's motivation for learning, Parvan K., Hosseini F.A. \& Bagherian S. (2018) in their study aimed to assess the relationship between the extent of the clinical nursing instructor's use of teaching behaviors and the effectiveness of these behaviors on students' learning at Tabriz University of Medical Sciences. The results indicated significant positive relationships between the extent to which clinical nursing instructors used teaching behaviors and the effectiveness of these behaviors on students' learning. In light of this relationship, the university authorities have to find strategies to employ clinical instructors that are efficient in using clinical teaching behaviors, and they should plan to empower their clinical instructors in this field. This result was in agreement with the preset study findings
[2] . Sadeghi A., Oshvandi K. \& Moradi Y. (2019) who titled their study by explaining the inhibitory characteristics of clinical instructors in the process of developing clinical competence of nursing students, the findings of this study illustrate the characteristics of a clinical instructor, which play a serious role in reducing the clinical development and creating the lack of clinical competence development of students. The existence of autocratic behaviors was one of the factors that many students described as one of the instructor's inhibitory features in their development process of clinical competence, which was associated with the lack of motivation, disappointment toward the nursing [16]. These results support the present study findings as it confirms the strong relation between teaching behaviors of clinical instructors and nursing student's motivation for learning. Another study Koy V. (2015) found process of becoming an excellent clinical instructor involved "change from instiller to facilitator and laid the foundation for continued development of teaching self. He summarized the need for continued education of the clinical instructors to motivate students to learn. This was in agreement with the present study recommendations of making basis for the recruitment, selection, and development of clinical instructors for the best of students learning that will in the future come back with benefit on their work as quality of care [17].

In the study of Prabha D., Bhari V., Ponchitra R., Divya K. \& Singh S. (2016) which is titled by Perceptions of nursing students on clinical teaching behaviors, discussed the behavior of clinical instructors, the association of actual teaching behavior and clinical learning, and the expected clinical teaching behavior of clinical instructors. they found a strong relation between teaching behaviors of clinical instructors and students learning. These results assured the present study findings as it confirms that there is a relationship between teaching behaviors of clinical instructors and students motivation for learning, besides this study recommended to formulate a program for newly clinical instructors for good preparation of them to their future roles to ensure high qualified nurse graduate [4]. It was concluded in the study of Ramzan S. (2017) that if clinical instructor use effective clinical teaching behaviors, it is extremely helpful for student learning. If he never used these effective behaviors, student learning will be affected badly. That also what is concluded from the present study about the importance of using the behaviors that motivate students to learn [18]. 


\section{Conclusion:}

Teaching behaviors of clinical instructors must be considered in relation to student's motivation for learning as there was significant positive relationship between clinical instructor's teaching behaviors and nursing student's motivation for learning.

\section{Recommendations:}

Based on the findings of the present study, the following can be recommended:

1- The results may be utilized to improve faculty awareness of students' perceptions on the characteristics of an effective clinical instructor.

2- Workshops/seminars should be organized to orient newly clinical instructors on their roles in clinical setting.

3- The study should be replicated in a larger population in different faculties and universities. Ex. governmental and private universities.

4- Periodic clinical instructors' evaluation is necessary to incorporate unused behaviors, into their practice.

5- Clinical instructors should use Nursing Clinical Teacher Effectiveness Inventory (NCTEI) as a self-assessment to help them in incorporating behaviors that motivate students to learn.

6- An orientation program should be prepared for newly clinical instructors.

\section{References}

1- MOHAMED ZAKARIA A. and ABDEL-RAHMAN GHEITH N.: Measurement of Effectiveness of Clinical Learning Environment for Nursing Faculty Students at Mansoura University, Egypt. IOSR Journal of Nursing and Health Science (IOSR-JNHS) e-ISSN: 2320-1940 Volume 4, Issue 3 Ver. III, PP 35-45 www.iosrjournals.org 2015.

2- PARVAN K., HOSSEINI F.A. and BAGHERIAN S.: The relationship between nursing instructors' clinical teaching behaviors and nursing students' learning in Tabriz University of Medical Sciences in 2016. Education for Health, 31 (1), 32. 2018.

3- LUDIN S.M. and FATHALLAH N.M.N.: Undergraduate nursing students' perceptions of the effectiveness of clinical teaching behaviors in Malaysia: A cross-sectional, correlational survey. Nurse education today, 44: 79-85, 2016.

4- PRABHA D., BHARTI V., PONCHITRAR., DIVIA K. and SINGH S.: Perceptions of nursing students on clinical teaching behaviors of teaching faculty: Correlational survey design. Journal of Nursing and Health Science (IOSR-JNHS), 2320-1959, 2016.

5- CARLWIMAN: Science Education Initiative, motivating learning, Available at www.cwsei.ubc.ca., 2013.
6- ISMAIL L.N., ABOUSHADY R.M. and ESEI A.: Clinical instructor's behavior: Nursing student's perception toward effective clinical instructor's characteristics. Journal of Nursing Education and Practice, 6 (2): 96-105, 2016.

7- KNOX J.E. and MOGAN J.: Important clinical teacher behaviors as perceived by university nursing faculty, students and graduates. J. Adv. Nurse. 10: 25-30. doi: 10.1111/j.1365-2648.1985.tb00488.x, 1985.

8- ZAKI S.: Motivation for learning and emotional intelligence and their relationship to academic achievement among preparatory school students in Gaza. A dissertation of doctorate, College of education. available at www.com 2015.

9- MADHAT G.K., SHUKRI R.K., HAYUDINI J. and NARAYANANS K.: Undergraduate nursing students' perception of effective clinical instructor: Oman. International Journal of Nursing Science, 3 (2): 38-44, 2013.

10- NELSON N.: Beginning nursing students' perceptions of the effective characteristics and caring behaviors of their clinical instructor (Doctoral dissertation, Capella University), 2011.

11- Caring Behaviors of Clinical Instructors during Nursing Students' Related Learning Experience: A Basis for Enhancing Student Mentor Relationship. Asia Pacific Journal of Multidisciplinary Research, 5 (1.2): 84-93, 2017.

12- ALIAKBARI F., PARVIN N., HEIDARI M. and HAAGHANI F.: Learning theories application in nursing education. Journal of Education and Health Promotion, 4, 2015.

13-HANIFI N., DELKHOSH M. and PARVIZY S.: Motivation in the Clinical Education of Nursing Students: A Hybrid Concept Analysis Method. Preventive Care in Nursing \& Midwifery Journal, 7 (4): 19-31, 2018.

14- ORSINI C., EVANS P. and JEREZ O.: How to encourage intrinsic motivation in the clinical teaching environment? A systematic review from the self-determination theory. Journal of Educational Evaluation for Health Professions, 12, 2015.

15- Al-HAMDAN Z., FOWLER J., BAWADI H., NORRIE P., SUMMERSL and DOWSETT D.: Student nurses' perceptions of a good mentor: A questionnaire survey of student nurses in the UK, USA and Jordan. International Journal of Humanities and Social Science, 4 (3): 248-56, 2014.

16- SADEGHI A., OSHVANDI K. and MORADI Y.: Explaining the inhibitory characteristics of clinical instructors in the process of developing clinical competence of nursing students: A qualitative study. Journal of family medicine and primary care, 8 (5): 1664, 2019.

17- KOY V.: Perceptions of nursing students on effective clinical preceptors in Phnom Penh National Hospitals, Cambodia. International Journal of Research in Medical Sciences, 3 (7): 1605, 2015.

18- RAMZAN S.: The behaviors of clinical nursing faculty toward Student learning. Saudi Journal of Medical and Pharmaceutical Sciences, ISSN 2413-4910 (Online). Website: http://scholarsmepub.com ., 2017. 


\section{العلاقة بين السلوكيات التدريسية

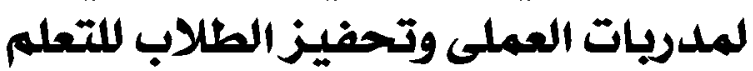

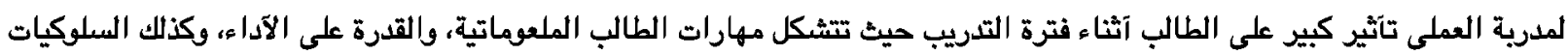

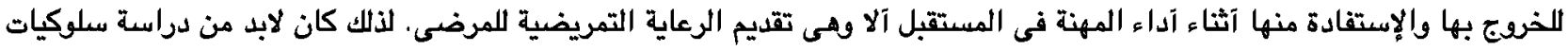

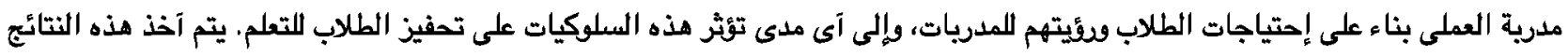

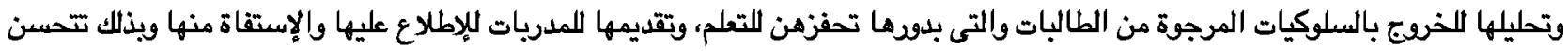
العملية التعليمية آثناء فترة التريب الناتجة عن حسن العلاقة بين الطالبة والمدربة.

عينة وآدوات البحث: تضمنت عينة البحث . عا طالبة المقيدات بالفرقة الرابعة بكلية التمريض - جامعة الآزهر واللاتى مرن بثلاثة أعوام

$$
\text { سابقة من الترريب العملى والترم الآتول من العام الرابع. }
$$

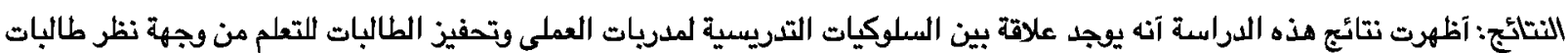

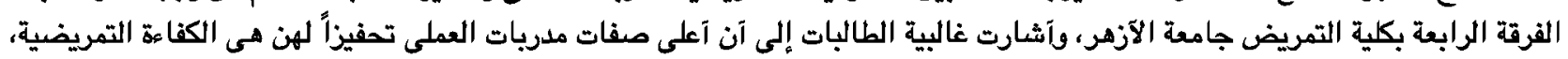

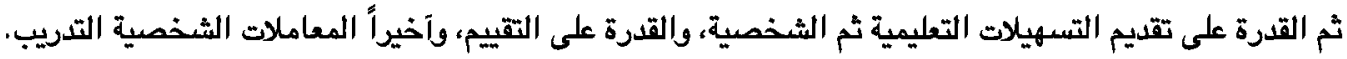

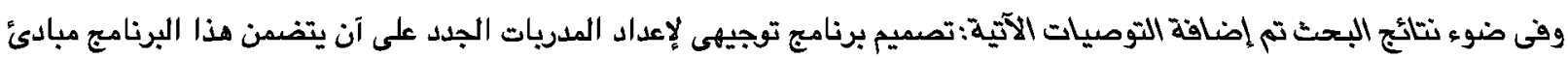

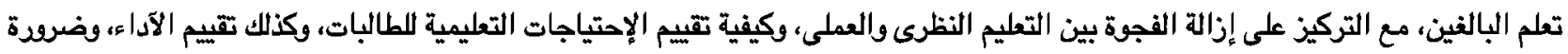
إتاحة الفرصة لهن المناقشة العمل الإكلينيكى، وتقويم قدراتهن على إتخاذ القرارات، وكيفية التعامل وحل الإشكالات آثَناء تدريب الطالبات، وتنمية الثاتية القدرة على الثقة بالنفس. 